\title{
Quantitative relationship between cupping of the optic disc and visual field loss in chronic simple glaucoma
}

\author{
J. GLOSTER
}

From the Institute of Ophthalmology, London

SUMMARY The extent of cupping was measured from optic disc photographs of 300 patients with ocular hypertension and suspected or established chronic simple glaucoma, and their visual fields were recorded. The incidence of field defects increased as the vertical cup:disc ratio increased, a value of 0.70 for this ratio being a particularly useful guide to the presence or absence of field loss. There was a significant correlation between the extent of cupping and the size of the visual field. The vertical cup:disc ratio was the most useful quantitative index of cupping.

The decision that cupping of the optic disc is pathological rather than physiological is of great importance in the diagnosis of chronic simple glaucoma. Sometimes this decision is difficult, and it is then helpful to correlate the result of a visual field examination, which must always be done, with the appearance of the disc. If it is thought, for example, that the edge of the cup is abnormally near to the edge of the disc in the inferotemporal sector, then the finding of an early upper arcuate scotoma supports the view that the cupping is pathological. In addition to a topographical relationship between disc damage and field loss, one may also attempt the more difficult judgment of whether the amount of glaucomatous cupping matches the amount of field loss. In practical clinical terms one tries to answer the question whether the visual field loss can be wholly accounted for by glaucoma, or whether some additional pathology has to be considered.

The relationship between glaucomatous damage to the optic nerve head and visual field loss has been examined in various ways: (1) By relating a particular feature of the disc to the presence or absence of a field defect or to the position or progression of the defect. The features of the disc which have received attention include the size and shape of the cup, pallor and notching of the neuroretinal rim, and haemorrhages (Chandler and Grant, 1965; Armaly, 1969, 1970; Read and Spaeth, 1974; Drance, 1975; Gloster, 1975; Hitchings and Spaeth, 1977; Drance et al., 1977). (2) By correlating the

Address for reprints: Professor J. Gloster, Institute of Ophthalmology, Judd Street, London WC1 H 9QS extent of glaucomatous cupping of the disc with the amount of field loss. In one study (Fisher et al., 1970) the extent of cupping was graded and the field loss was measured, while in another study (Gloster, 1976) cup:disc ratios were measured and the field loss was divided into 4 grades.

The purpose of the present paper is: (1) to determine the incidence of demonstrable glaucomatous field defects at various values of the vertical cup:disc ratio; (2) to correlate the amount of field loss with quantitative expressions of glaucomatous damage to the disc.

\section{Methods}

\section{PATIENTS}

All the information used was derived from fundus photography and visual field examinations which formed part of the routine investigation of patients attending the Glaucoma Clinic at the Institute of Ophthalmology, London. The patients were either glaucoma suspects, cases of ocular hypertension, or established cases of chronic simple glaucoma, and all had shown at some time an intraocular pressure greater than $20 \mathrm{mmHg}$.

\section{FUNDUS PHOTOGRAPHY AND MEASUREMENTS} OF CUPPING OF THE OPTIC DISC

These procedures have been fully described in previous papers (Gloster and Parry, 1974; Gloster, 1975). The cup:disc ratios used in the present study are: (1) the vertical cup:disc ratio, that is, the vertical diameter of the cup divided by the vertical diameter of the disc; (2) the horizontal cup:disc ratio, that is, the analogous ratio of the horizontal 
diameters; (3) the area ratio that is, the area of the cup divided by the area of the disc; (4) the rim: diameter ratio, that is, the narrowest part of the rim of the cup divided by the diameter of the disc.

\section{VISUAL FIELD TESTING}

Each patient was examined in three ways: (1) The central field was tested with the Globuck screen (Buchanan and Gloster, 1965). This presents stimuli as flashes in 74 fixed positions in the central field. The extent of the field was expressed as the number of stimuli seen by the patient. (2) The central field was also examined on the Goldmann perimeter with the 1:4 stimulus presented as a flash in 188 fixed positions as described by Gloster (1970). Again, the number of stimuli seen was used to express the extent of the field. (3) The peripheral and central fields together were tested on the Goldmann perimeter by kinetic perimetry with the $1: 4$ stimulus. The area of seeing field as plotted on the chart was measured by means of a planimeter.

\section{Results}

\section{INCIDENCE OF GLAUCOMATOUS FIELD}

DEFECTS AT VARIOUS VALUES OF THE

VERTICAL CUP :DISC RATIO

Table 1 summarises the findings for 300 eyes. In 150 eyes there was no associated field defect, these results relating either to patients with ocular hypertension or to those with chronic simple glaucoma with unilateral field loss. In the remaining 150 eyes there was glaucomatous field loss. Table 1 shows that there was a particularly rapid increase in the incidence of field defects when the vertical cup:disc ratio attained a value of about 0.70 . If this value was used to separate eyes which would be expected to show a glaucomatous field defect from those which would not, it was found that a correct separation could be made for $87 \%$ of the eyes. The accuracy with which the vertical cup:disc ratio could be measured depended greatly on the certainty with which the position of the edge of the cup could be defined. When the disc photographs were measured, a note was made of whether the observer was certain, fairly certain, or doubtful of the position of the cup edge. It should be emphasised that this was a matter not of the quality of the photograph but of the actual appearance of the disc, and this conforms to the common clinical experience that in some discs it is easy to say how much is cupped while in others it is difficult. Table 2 shows how certainty or uncertainty about the edge of the cup affected the use of a cup:disc ratio of 0.70 for separating eyes with field defects from those with full fields. It is clear that doubt about the cup edge
Table 1 The incidence of glaucomatous field defects at various values of the vertical cup:disc ratio

\begin{tabular}{lc}
\hline Vertical cup: disc ratio & Incidence of field defect \\
\hline & $(\%)$ \\
$0.90-0.99$ & 100 \\
$0 \cdot 80-0.89$ & 95 \\
$0 \cdot 70-0.79$ & 65 \\
$0 \cdot 60-0.69$ & 20 \\
$0 \cdot 50-0.59$ & 4 \\
$0 \cdot 40-0.49$ & 6 \\
$0.30-0.39$ & 0
\end{tabular}

300 eyes: 150 with field defects. 150 with full fields.

Table 2 The effect of uncertainty about the position of the cup edge on the use of the vertical cup:disc ratio for separating eyes with field defects from those with full fields

\begin{tabular}{lll}
$\begin{array}{l}\text { Position of } \\
\text { cup edge }\end{array}$ & $\begin{array}{l}\text { No. of } \\
\text { eyes }\end{array}$ & $\begin{array}{l}\text { Correct } \\
\text { separation }\end{array}$ \\
\hline Certain & 131 & $(\%)$ \\
Fairly certain & 84 & 94 \\
Doubtful & 85 & 87 \\
\hline
\end{tabular}

Table 3 Mean vertical cup: disc ratios for eyes with full fields and for eyes with early, intermediate, and glaucomatous field loss

\begin{tabular}{ll}
\hline Field loss & Mean vertical cup: disc ratio \\
\hline $\begin{array}{l}\text { None } \\
\mathrm{n}=150\end{array}$ & 0.57 \\
$\begin{array}{c}\text { Early } \\
\mathrm{n}=50\end{array}$ & 0.76 \\
$\begin{array}{c}\text { Intermediate } \\
\mathrm{n}=50\end{array}$ & 0.80 \\
$\begin{array}{c}\text { Advanced } \\
\mathrm{n}=50\end{array}$ & 0.88 \\
\hline
\end{tabular}

had a marked effect. When there was no doubt about the extent of cupping, use of the vertical cup: disc ratio allowed a correct statement to be made about the presence or absence of a field defect in $94 \%$ of eyes.

\section{CORRELATION OF FIELD LOSS WITH} CUP :DISC RATIOS

Table 3 gives the mean vertical cup:disc ratios for the same group of 300 eyes as in Table 1.150 eyes had full fields (and an intraocular pressure $>20$ $\mathrm{mmHg}$ ) and 150 had glaucomatous field loss. According to the severity of the field loss a division could be made into three subgroups: (1) 50 eyes with an early defect consisting of a paracentral or arcuate scotoma; (2) 50 eyes with an intermediate defect consisting of an arcuate scotoma breaking 
Table 4 The correlation of disc measurements and visual fields

\begin{tabular}{|c|c|c|c|c|}
\hline & \multicolumn{4}{|c|}{ Correlation coefficients } \\
\hline & $\begin{array}{l}\text { Vertical } \\
\text { cup:disc } \\
\text { ratio }\end{array}$ & $\begin{array}{l}\text { Horizontal } \\
\text { cup:disc } \\
\text { ratio }\end{array}$ & $\begin{array}{l}\text { Area } \\
\text { cup:disc } \\
\text { ratio }\end{array}$ & $\begin{array}{l}\text { Rim: diameter } \\
\text { ratio }\end{array}$ \\
\hline $\begin{array}{l}\text { Goldmann perimeter, central and peripheral } \\
\text { field together, kinetic method }\end{array}$ & -0.69 & -0.55 & -0.66 & 0.56 \\
\hline $\begin{array}{l}\text { Goldmann perimeter, central field only, } \\
\text { stat ic method }\end{array}$ & -0.79 & -0.55 & -0.67 & 0.69 \\
\hline
\end{tabular}

out to the periphery with loss of a nasal quadrant; (3) 50 eyes with an advanced defect, in which a small central island remained, sometimes together with a temporal island. It can be seen that there was a progressive increase in the mean vertical cup:disc ratio as the visual field became smaller.

In order to investigate further the relationship between the size of the cup and the amount of field loss, results were analysed from 40 eyes with field loss, in all of which there was no doubt about the position of the whole of the edge of the cup. Only 1 eye from each patient was included in this analysis. Correlation coefficients were calculated between the size of the visual field and the vertical and horizontal cup:disc ratios, the area ratio, and the rim:diameter ratio; the values obtained are given in Table 4 and all were highly significant $(P<0.001)$. By contrast, the maximum untreated intraocular pressures for this group of patients showed no significant correlation with field loss $(P=0 \cdot 152)$. In the case of the vertical, horizontal, and area cup:disc ratios the correlation with the size of the visual field was negative, as would be expected, because the larger the cup the greater the field loss. The correlation was positive for the rim:diameter ratio because the narrower the rim the greater the incidence of field loss.

From Table 4 it can be seen that: (1) the best correlation was between the vertical cup:disc ratio and the central field obtained on the Goldmann perimeter by the static method; (2) the field loss was more closely related to the vertical cup:disc ratio than to the horizontal cup:disc ratio, there being a significant difference $(P<0.05)$ between the two correlation coefficients $(-0.79$ and -0.55$)$ for the central Goldmann field.

Figs. 1 and 2 show the relationship of the vertical and horizontal cup: disc ratios to the size of the visual field. In each case the linear regression line has been drawn, although it is an assumption that the relationship is linear. The greater scatter of the horizontal ratios than of the vertical ratios can be seen.

\section{Discussion}

The results given show that in general the size of the cup in an optic disc can be related quantitatively to the incidence and extent of glaucomatous field loss, although there is a wide variation which limits the application of this quantitative relationship to the individual patient.

It is of interest to note from Table 3 that there is a considerable increase in the vertical cup:disc ratio in eyes with early glaucomatous field defects as compared with eyes which had intraocular pressures over $20 \mathrm{mmHg}$ but full fields. This observation supports the idea that it is useful to undertake periodic photography of the optic disc in the supervision of cases of ocular hypertension because it suggests that enlargement of the cup could be detected before a scotoma became evident.

The view previously expressed that the vertical cup:disc ratio is more useful clinically than the horizontal cup:disc ratio (Gloster and Parry, 1974; Gloster, 1975) receives further support from the study of the correlation of these ratios with the extent of field loss (see Table 4 and Figs. 1 and 2). It is possible to use the vertical cup:disc ratio to differentiate, with a fair degree of accuracy, between discs which are associated with a glaucomatous field defect (that is 'glaucomatous' discs) from those which are associated with full fields (that is, 'probably non-glaucomatous' discs). The efficiency of this method of recognising glaucomatous discs depends on the certainty with which the upper and lower edges of the cup can be recognised. The practical outcome of these results is that when the judgment has to be made with the ophthalmoscope as to whether cupping is physiological or pathological special attention should be paid to the upper and lower margins of the cup. If there is uncertainty about the edges of the cup, the pupil should be dilated (with due regard to the width of the angle), and the disc should be examined with the slit-lamp and Hruby or fundus contact lens. If a reasonably accurate estimate of the vertical cup:disc ratio can 


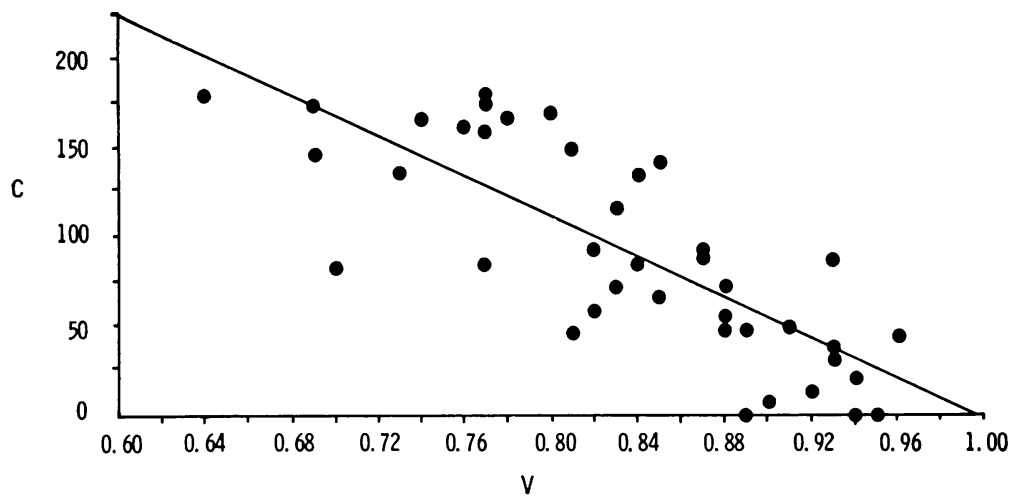

Fig. 1 The relationship between the size of the visual field and the vertical cup: disc ratio. Ordinate: $\mathrm{C}=$ number of stimuli seen in central field on Goldmann perimeter. Abscissa: $\mathrm{V}=$ vertical cup:disc ratio

Fig. 2 The relationship between the size of the visual field and the horizontal cup:disc ratio. Ordinate: as in Fig. 1. Abscissa: $\mathrm{H}=$ horizontal cup:disc ratio

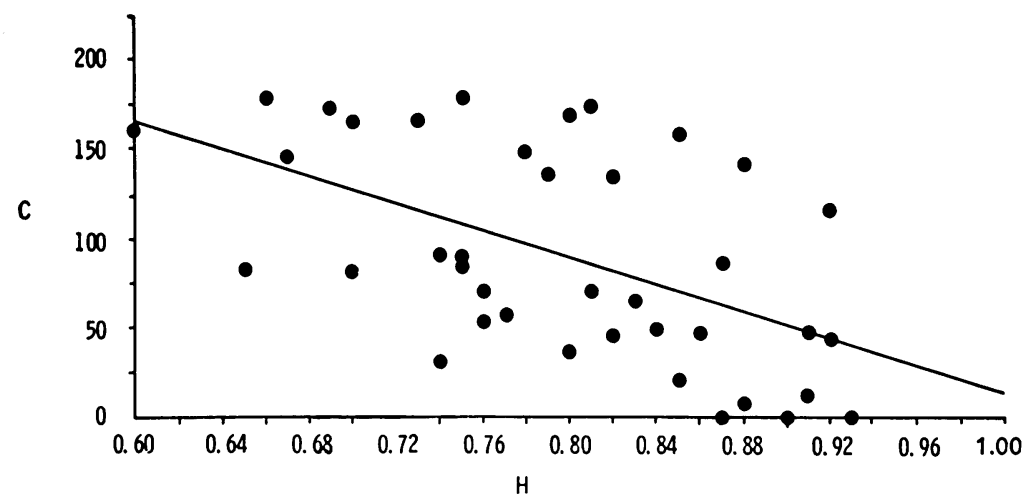

be made (and this is often possible from ophthalmoscopic or slit-lamp examination), the data in Table 1 give an indication of the probability that the disc is or is not glaucomatous.

If the data of Table 1 are translated into clinical probabilities and applied to eyes with tensions greater than $20 \mathrm{mmHg}$, the following can be said: (1) If the vertical cup:disc ratio is less than $0 \cdot 4$, there is a very low probability that the disc is glaucomatous. (2) With values of the ratio between 0.4 and 0.6 , the chances are about 1 in 20 that the disc is glaucomatous. (3) When the ratio is between 0.6 and 0.7 the chances are 1 in 5 that the disc is glaucomatous. (4) At a value of about 0.7 for the vertical cup:disc ratio there is a very rapid increase in the chances that a disc is glaucomatous. (5) When the ratio is between 0.7 and 0.8 , the chances are 2 to 1 that the disc is glaucomatous, rising to almost 20 to 1 for ratios between $0 \cdot 8$ and $0 \cdot 9$. (6) When the ratio exceeds 0.9 the disc is certainly glaucomatous.

The factor of variation allows us to make a statement of probability only, but in this respect we are in the same situation as with measurements of intraocular pressure and their relationship to the diagnosis of glaucoma, except that observations on the disc are more closely related to loss of visual function than are measurements of intraocular pressure. Quite apart from giving a more precise statement of the probability of glaucomatous change in the individual patient, the vertical cup: disc ratio may be of use in research projects as a quantitative objective index of the stage to which glaucoma has progressed.

I am very grateful to Mr D. Poinoosawmy for technical assistance, $\mathrm{Mr} \mathrm{H}$. Donovan for computer analysis of the results, and $\mathrm{Mr} \mathrm{R}$. Fletcher for the illustrations.

\section{References}

Armaly, M. F. (1969). The correlation between appearance of the optic cup and visual function. Transactions of the American Academy of Ophthalmology and Otolaryngology, 73, 898-913.

Armaly, M. F. (1970). Optic cup in normal and glaucomatous eyes. Investigative Ophthalmology, 9, 425-429.

Buchanan, W. M., and Gloster, J. (1965). Automatic device 
for rapid assessment of the central visual field. British Journal of Ophthalmology, 49, 57-70.

Chandler, P. A., and Grant, W. M. (1965). Lectures on Glaucoma, Chapter 1. Kimpton: London.

Drance, S. M. (1975). Correlation of optic nerve and visual field defects in simple glaucoma. Transactions of the Ophthalmological Societies of the United Kingdom, 95, 288-296.

Drance, S. M., Fairclough, M., Butler, D. M., and Kottler, M. S. (1977). The importance of disc haemorrhage in the prognosis of chronic open angle glaucoma. Archives of Ophthalmology, 95, 226-228.

Fisher, R. F., Carpenter, R. G., and Wheeler, C. (1970). Assessment of established cases of chronic simple glaucoma. British Journal of Ophthalmology, 54, 217-228.

Gloster, J. (1970). Flash perimetry. British Journal of Ophthalmology, 54, 649-658.
Gloster, J. (1975). Vertical ovalness of glaucomatous cupping. British Journal of Ophthalmology, 59, 721-724.

Gloster, J. (1976). In: Recent Advances in Glaucoma. Edited by S. Rehak and G. Paterson. International Glaucoma Symposium, Prague, 1976. Springer-Verlag: Berlin.

Gloster, J., and Parry, D. G. (1974). Use of photographs for measuring cupping in the optic disc. British Journal of Ophthalmology, 58, 850-862.

Hitchings, R. A., and Spaeth, G. L. (1977). The optic disc in glaucoma. II: Correlation of the appearance of the optic disc with the visual field. British Journal of Ophthalmology, 61, 107-113.

Read, R. M., and Spaeth, G. L. (1974). The practical clinical appraisal of the optic disc in glaucoma: the natural history of cup progression and some specific disc-field correlations. Transactions of the American Academy of Ophthalmology and Otolaryngology, 78, 255-274. 